\title{
Using normative scenarios in landscape ecology
}

\author{
Joan Iverson Nassauer ${ }^{1, *}$ and Robert C. Corry ${ }^{1,2}$ \\ ${ }^{1}$ School of Natural Resources and Environment, 430 E. University Avenue, University of Michigan, Ann Arbor, \\ MI, USA.; ${ }^{2}$ School of Environmental Design \& Rural Development, University of Guelph,, Guelph, Ontario, \\ N1G 2W1, Canada; *Author for correspondence (e-mail: nassauer@umich.edu)
}

Received 31 July 2002; accepted in revised form 6 April 2003

Key words: Agriculture, Futures, Interdisciplinary, Landscape change, Planning, Policy, Scenarios

\begin{abstract}
The normative landscape scenario is one of many types of scenario methods that are used by landscape ecologists. We describe how normative landscape scenarios are different from other types and how these differences create special potential for engaging science to build landscape policy and for exploring scientific questions in realistic simulated landscapes. We describe criteria and a method for generating normative scenarios to realize this potential in both policy and landscape ecology research. Finally, we describe how the method and criteria apply to an interdisciplinary project that proposed alternative scenarios for federal agricultural policy and related futures for agricultural watersheds in Iowa, USA.
\end{abstract}

\section{Introduction}

Applying landscape ecology research to policy, planning, design, and management has been an intrinsic, if challenging, goal of the field since its inception (Risser et al. 1984; Hobbs 1997; Turner et al. 2001; Opdam et al. 2002). At the same time, issues raised by these applications have informed research agendas in landscape ecology (Franklin and Forman 1987; Turner and Romme 1994; Hansson et al. 1995; Gustafson and Crow 1998; Ribe et al. 1998; Keane et al. 1999). Scenario approaches have been suggested as a means of integrating the science of landscape ecology with landscape planning (Ahern 2001; Opdam et al. 2002), and a wide array of scenario approaches is being used by landscape ecologists (Freemark et al. 1996; RIZA 1996; White et al. 1997; Swetnam et al. 1998; Bierzychudek 1999; Hamblin 1999; Johnson et al. 1999; Pearson et al. 1999; Hulse et al. 2000; Keitt 2000; Wickham et al. 2000; Jenerette and Wu 2001; Steinitz and MacDowell 2001; Hawkins and Selman 2002; Tress and Tress 2003). More broadly, scenarios have been used to anticipate environmental and human effects of trade, agricultural, forestry, and land use policy - including climate change and biodiversity loss (Schwartz 1991; Caza and Kaarik 1994; Cocks 1999; Sala et al. 2000; Tilman et al. 2001; Peterson et al. 2003). Within this wide array, normative landscape scenarios have particular potential for constructing more explicit, relevant relationships between the science of landscape ecology and policy. In this paper we distinguish normative landscape scenarios as one type, we describe criteria for generating normative landscape scenarios that contribute to both policy and landscape ecology research, and we describe how these criteria apply to an interdisciplinary project that proposed alternative scenarios for federal agricultural policy and developed alternative futures for agricultural watersheds in Iowa, USA, (Santelmann et al. 2001; Nassauer et al. 2002; Santelmann et al. 2004). 


\section{What are normative landscape scenarios?}

All scenarios are vivid stories that are constructed to describe alternative futures or contrasting trends that might be very different from the present. They allow decision-makers to anticipate their reactions to different future possibilities, to anticipate time-frames beyond the immediate future, and to make choices (Schwartz 1991; Schoonenboom 1995; Samson and Knopf 1996; Cole 2001; Peterson et al. 2003). They should include a description of the present situation, a number of alternative futures, and possible pathways connecting the present with images of the future (Schwartz 1991; Schoonenboom 1995). Alternative futures then can be evaluated and compared (Steinitz 2002; RIZA 1996; Swetnam 1998; Hulse et al. 2000).

In landscape planning, 'scenario' refers to the different possible stories, or alternative assumptions, that underlie landscape change (e.g., policy); the landcover pattern and functional consequences that may be an outcome of the scenario is referred to as a 'future' (Steinitz et al. 2003). For landscape scenarios, the alternative futures are explicit, spatially-specific representations of landcover patterns: maps, digital imaging simulations, or, even drawings, rather than only quantitative outcomes (Swetnam et al. 1998; Countryman and Murrow 2000; Hawkins and Selman 2002). This alone has implications for policy: allowing decision-makers and the broader public to literally see the alternatives.

For landscape ecology, these images of the future have an additional advantage: they depict landscape patterns that can be generated and tested by interdisciplinary thinking (Peterson et al 2003). Maps encoded as appropriately scaled and classified coverages in geographic information systems (GIS) allow experts from different disciplines to make inferences from a single landscape pattern to a wide array of ecological, economic, and cultural functions.

Normative landscape scenarios are distinctive in that they portray futures that should be (Emmelin 1994; Ahern 2001; Wachs 2001; Hulse et al. 2002; Opdam et al. 2002). They can inspire policy by providing images of landscapes that could meet societal goals. Normative futures may not yet exist, but they plausibly could exist. The science of landscape ecology is particularly apt as a basis for developing normative scenarios because it allows scenario designers to experiment with inventing landcover patterns that are expected to have selected ecological functions that society values (e.g., RIZA 1996; Swetnam et al. 1998; Hulse et al. 2000; Ahern 2001). These functions can be articulated as hypotheses about how particular landscape patterns and management regimes produce related landscape functions and values. Hypothesized functions and values can then be tested against ecological, economic, and cultural models or empirical data.

Normative scenarios formulated to embody hypotheses about landscape functions should be distinguished from normative scenarios developed by stakeholders in a particular landscape. Scenarios that embody stakeholder values and choices about landscape pattern can be very helpful in pointing out the implications of potential decisions about particular landscapes. Developing these scenarios can engage stakeholders in articulating their values, building consensus, or understanding a problem (e.g., Ralls and Starfield 1995; Jones 1999; Ahern 2001; Wachs 2001; Ahern et al. 2002; Hulse et al. 2002; Peterson et al. 2003; Tress and Tress 2003). Normative scenarios that embody hypotheses about landscape functions are helpful in a different way. They rely on science to invent landscape patterns that may not be imaginable to stakeholders, but that are hypothesized to have certain ecological, economic, or cultural effects (Fry 2001). For example, a scenario developed by stakeholders might engage citizens in envisioning alternative locations for residential development in a rural area, and the habitat effect of the alternative futures could then be measured. In contrast, a scenario developed to test landscape hypotheses might engage scientists in inventing new patterns for residential development that are hypothesized to minimize habitat loss in a rural area and then test the habitat functions of the resulting landscape pattern. The difference lies in the capacity to invent new patterns for their explicit functional intent.

Normative futures that imagine new landscape patterns as hypotheses sometimes may be very different from futures that stakeholders describe. Both citizen stakeholders, who may not know the functional implications of the landscape patterns they imagine, and expert stakeholders, who may not believe that policy or behavioral change to make new landscape patterns is possible, may envision future landscapes more narrowly than interdisciplinary teams envisioning hypothetical landscapes for their functional potential.

All normative scenarios are different from projective scenarios, which describe what the future is likely to be within a confidence interval of uncertainty 
that may be depicted as 'high' and 'low' extensions of the trend. Normative scenarios fall within the type, prospective scenarios, that describes how the future could be, what might be a 'reachable' future (Schoonenboom 1995; Beck 2002). Prospective scenarios are more useful than projective scenarios in situations in which uncertainty is great and uncontrollable (Peterson et al. 2003) or simply inadequately acknowledged (Varis 2002); imaginative new ideas are needed to address intractable or surprising policy challenges (Schwartz 1991); technological, political, or cultural change could create a context for future behavior that is very different from the past (Schwartz 1991; Beck 2002); or projective scenarios cannot adequately capture expert knowledge of interactions among model variables (Varis 2002). Hammond (1998, p. 9) argues, 'trends cannot be the only guide to the future, because the unexpected can occur, producing both happy and unhappy surprises'.

While all prospective scenarios depict futures that may not be predictable, the specific type, normative scenarios, has the goal of generating desirable futures that are plausibly but not necessarily assuredly achievable. This is different from projective scenarios, which extend quantified trends of past change, prospective scenarios that focus on understanding processes that could lead to surprising outcomes, or prospective scenarios that anticipate undesirable, frightening future states and model the probability of their occurrence (Science Advisory Board 1995; Beck et al. 2002; Varis 2002; Peterson et al 2003). Normative scenarios make an additional, different niche for science in the scenario development process.

For normative scenarios, desirable future states lead to process questions and models rather than process models leading to future states. Developers of normative landscape scenarios must hypothesize what landscape patterns will achieve desired outcomes, and then test whether the hypothesized landscape patterns and management regimes achieve those outcomes. Using normative scenarios, biogeochemical models can be used to examine outcomes of alternative futures, but futures are not determined by models of biogeochemical process. Rather futures are determined by plausible, selected, explicit assumptions (e.g., public values and policy) and expectations (e.g., hypotheses about function) that construct scenarios, vivid stories about landscape change.

Specific landscape futures are generated by land use/landcover allocation models (Hulse et al. 2002), but these models are driven by the assumptions and expectations that make up each scenario. The process of building normative landscape scenarios translates societal values (e.g., we want clean groundwater, or we want rural landscapes in the county) into testable scientific hypotheses about the effects of landscape change. It assumes a societal value about the ecological function of the landscape (in comparison with different values), and this value can be interpreted by scientific hypotheses about what patterns achieve it.

These distinctions invite landscape ecology into policy in powerful ways: by explicitly making expert hypotheses about landscape pattern:process relationships part of an inventive scenario design process, by testing expert hypotheses from many disciplines on the same invented landscapes, and by testing hypotheses in landscape futures that embody a high degree of realism (Tischendorf 2001).

\section{Criteria and a method for developing normative landscape scenarios}

These purposes can be realized by attention to several questions and choices when landscape ecologists use a normative landscape scenario development method (Table 1). The first three questions in Table 1 (I, II, III) provide a description of the present, pathways from the present to the future, and a description of the future. The fourth question in Table 1 (IV) asks: How does the performance of the futures compare? Addressing this question informs policy-makers and the public about likely effects if new policies were adopted. It also allows scientists to test pattern:process relationships on novel, experimental, but highly realistic landscapes. While the scenario development method might be characterized for policy-makers and the public by the four questions (I-IV) in Table 1, those same four questions can be characterized for science as:

1) Collecting existing data,

2) Formulating and operationalizing hypotheses,

3) Generating new data, and

4) Testing hypotheses.

While Table 1 describes sequential questions, normative scenario design is an iterative process (Figure 1). Question I, 'What is relevant about the present landscape and its past?' can be answered only in reference to Question II, 'How should the landscape change?' This question is at the heart of normative scenario design, and it is fundamentally a societal question. It depends upon what people (people living in a region, people formulating policy, people work- 
Table 1. Components and considerations in a normative scenario development process for landscape ecology

\begin{tabular}{|c|c|c|}
\hline Components & Questions addressed by that component & Considerations for answering these questions \\
\hline \multicolumn{3}{|c|}{$\begin{array}{l}\text { I. EXISTING DATA } \\
\text { The past and present landscape: what is relevant about the existing landscape and its past? }\end{array}$} \\
\hline Present landscape pattern (Data) & $\begin{array}{l}\text { a For future landscape goals and desirable char- } \\
\text { acteristics, what is relevant about the existing } \\
\text { landscape? }\end{array}$ & $\begin{array}{l}\text { Select coverages, data resolution, and classifi- } \\
\text { cation schemes that will provide information } \\
\text { necessary for component II. }\end{array}$ \\
\hline Past landscape pattern (Data) & $\begin{array}{l}\text { b What does change from the past to the } \\
\text { present imply about the future landscape? }\end{array}$ & $\begin{array}{l}\text { Select coverages, data resolution and classifi- } \\
\text { cation that will provide information necessary } \\
\text { for component II. }\end{array}$ \\
\hline
\end{tabular}

II. FORMULATE HYPOTHESES

Alternative future landscapes: how should the landscape change?

Future landscape policy goals (As- a What are plausible goals for future landscape Select broadly characterized landscape change sumptions) policy? goals (e.g., Enhance indigenous biodiversity) and assumptions that make those goals plausible by considering:

- past policy precedent,

- citizen stakeholder opinions/preferences,

- didactic purposes, and/or

- scientific questions that can be tested with realistic landscape patterns

Desirable landscape characteristics (Hypotheses)

Land allocation models (Operational- c What characteristics of existing landcover and ized hypotheses) b What characteristics of landcover: location relative to other characteristics, configuration, composition, management could help to achieve those goals?

other coverages indicate the location of future landcovers?
Engage experts from disciplines that encompass the range of policy goals and plausibility assumptions to prescribe and/or invent landcover characteristics.

Translate expert proposals for desirable landcover characteristics into landcover transition formulae with realism and precision. Consult component I.

\section{NEW DATA}

Alternative future landscapes: what is relevant about how the landscape could be?

\begin{tabular}{lll}
\hline Alternative futures (New data) & a Do the land allocation models produce the & $\begin{array}{l}\text { Iteratively test future landscape patterns } \\
\text { landscape characteristics that were proposed? } \\
\text { against expert expectations for the whole, in- } \\
\text { tegrated pattern. Consult II a and b. }\end{array}$ \\
\hline
\end{tabular}

IV. TEST HYPOTHESES

Evaluation of alternative landscape patterns: how does their performance compare?

\begin{tabular}{|c|c|c|c|}
\hline Disciplinary measures (Test) & $\mathrm{a}$ & $\begin{array}{l}\text { All of these components ask this question: } \\
\text { How do the alternative futures (and any rel- }\end{array}$ & $\begin{array}{l}\text { Santelmann, et al, in this issue describe evalu- } \\
\text { ation criteria of: }\end{array}$ \\
\hline Disciplinary models (Test) & $\mathrm{b}$ & & $\begin{array}{l}\text { - realism, } \\
\text { - accuracy, }\end{array}$ \\
\hline Pattern metrics (Test) & $\mathrm{c}$ & & $\begin{array}{l}\text { - precision, } \\
\text { - typical data availability, and }\end{array}$ \\
\hline Integrated assessment (Test) & $\mathrm{d}$ & & - scale of application. \\
\hline Risk assessment (Test) & $\mathrm{e}$ & $\begin{array}{l}\text { What alternatives that have similar overriding } \\
\text { goals but are somewhat different in pattern } \\
\text { produce notable differences of performance, } \\
\text { or thresholds? }\end{array}$ & $\begin{array}{l}\text { Vary futures by selecting aspects of: proposed } \\
\text { policy, futures landscape characteristics, or } \\
\text { spatial pattern of adoption that could affect } \\
\text { performance. }\end{array}$ \\
\hline
\end{tabular}




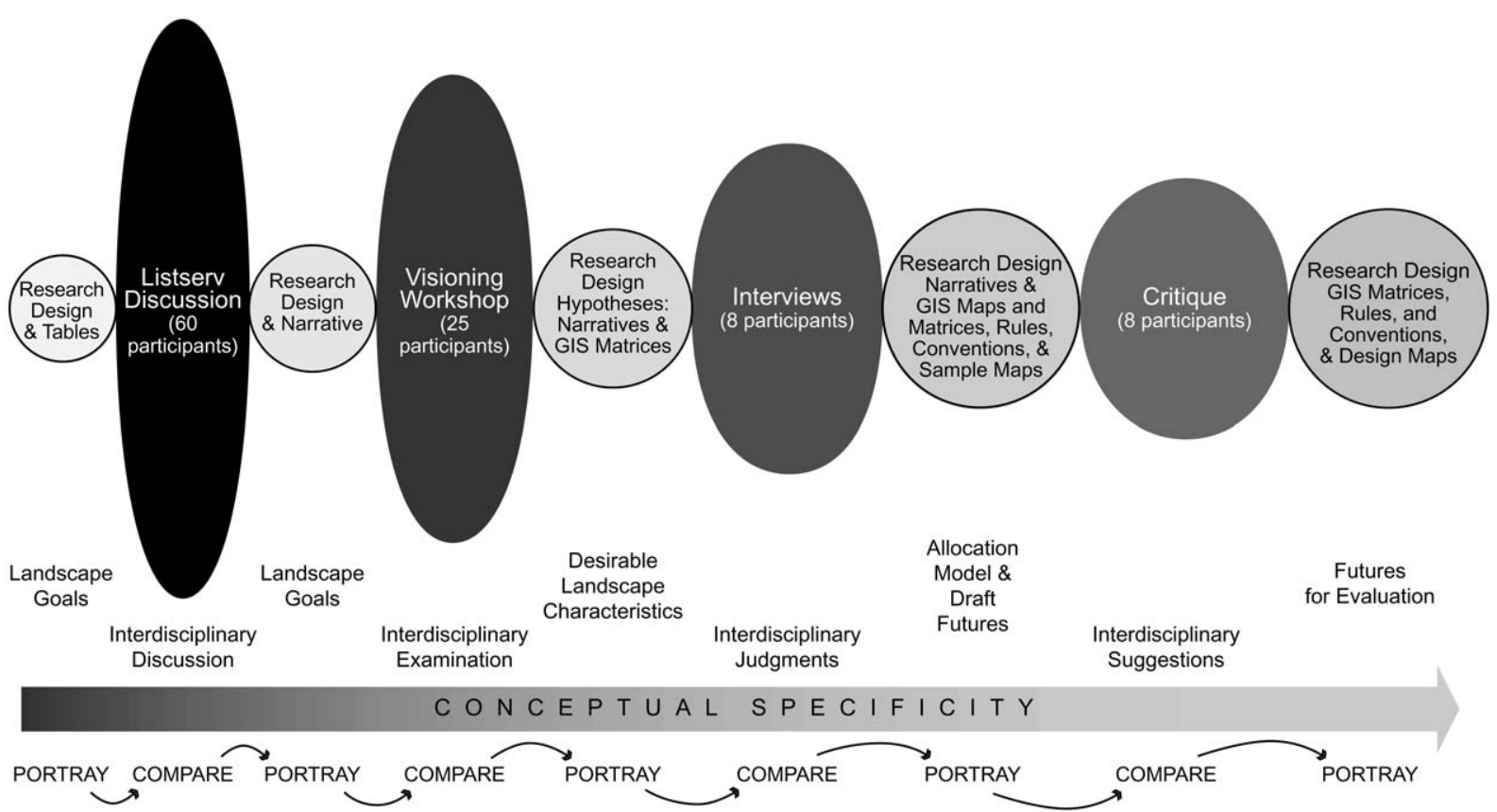

Figure 1. The iterative process we used to identify policy goals, propose desirable landscape characteristics, and develop landcover llocation models for Corn Belt agriculture landscape futures in 2025.

ing together in research, or some other group) think is valuable to explore and envision. The future policy goals that are selected (IIa) are essentially assumptions about what policy might possibly be (Cole 2001; Wachs 2001). These goals should be selected imaginatively, where the burden of argument is to show that some proposed goal is implausible rather than to show that it is likely (Schwartz 1991). A purpose of normative scenarios is to inspire policy; often, what will inspire has not been experienced in the past. Similarly, what people do or value now may not circumscribe how they would respond to something new in the future. For normative landscape scenarios, plausibility depends upon what qualitative changes in public values, technology, and policy orientation or economic support for policy can be credibly asserted rather than what has happened to landscapes in the past. Normative scenarios should give the public and policy-makers something to aim for rather than being limited to rearranging extant landcover patterns. The future policy goals that drive normative landscape scenarios should be imaginative, speculative, or didactic assumptions about societal values. The goals should be plausible, but the plausibility criterion is inspiration for policy action rather than probability of landscape change.
In the context of these goals, experts can form hypotheses about landscape pattern characteristics that will achieve societal goals for ecological processes (IIb). These hypotheses should not be limited to existing types of landscape characteristics. Hypotheses that invent new landscape patterns support landscape ecology hypothesis testing, and they may inspire policy to change landscapes. Forming these hypotheses is an interdisciplinary process that can be highly iterative as the many ecological, economic, and cultural processes implied by a single landscape pattern are considered (Figure 1). Scenario developers must select what characteristics of landscape change are plausible within the context of the selected policy goals (IIa), and they must explicitly articulate sets of pattern characteristics (location, configuration, composition, and management) that they hypothesize to exhibit desired characteristics of ecological, economic, or cultural processes.

The content of the hypotheses will determine what is relevant for Question I: what existing data (I) are needed to generate alternative landscape futures (III)? The resolution and classification of both existing data and the new data generated by land allocation models (IIc) as landscape futures should meet criteria of realism and experimental adequacy. Data should be at a high enough resolution and classified with 
enough conceptual detail to exhibit landscape characteristics the policy audience will recognize as germane for making decisions. This means paying attention to the scale at which landscape decisions are being made and implemented (e.g., pattern within a field, a farm, or across a metropolitan area). Data also should be at the right resolution and classification to give scientists the information needed to test hypotheses about landscape function. This may mean specifying how landcover will be managed (e.g., when perennial grasses will be mown or what amount of fertilizer will be applied).

Integrating all of these hypotheses in a single landscape pattern requires a highly iterative process in which landscape futures are created by land allocation models of explicit, replicable formulae for landcover change (IIc), and the resulting 'draft' futures are tested against the expectations of the experts, asking: is this the pattern you hypothesized (Figure 1)? Essentially, these land allocation models operationalize the hypothesized desirable landcover characteristics, determining what aspects of the characteristics will be possible to test. Landcover characteristics may include: location, configuration, composition, and management of landcovers. The futures should be explicit, replicable, and sufficiently precise to allow experts to evaluate their effects through modeling, survey research, or by other methods.

To judge the adequacy of a future, a criterion of replicability (design decisions determined by explicit rules) is more useful than a criterion of objectivity (design decisions determined by accepted facts). Objectivity can be confused with implicit selection of scenario design assumptions, in which 'everyone' knows the future will have some characteristic, like continued increasingly large agricultural field equipment. When such implicit assumptions are accepted as facts, they may insufficiently represent the multiple social interests and preferences that will be affected (Bantayan and Bishop 1998), and they may obstruct experiments with pattern. Normative scenarios do not assert that ' $X$ ' will happen; they provide an informed basis for the decision-maker to speculate upon what it might mean if ' $X$ ' did happen, whether ' $X$ ' is desirable, and what decisions might encourage or discourage ' $X$ ' to happen.

The futures also must meet the realism criterion displaying futures with adequate spatial and conceptual detail to recognizably address policy concerns. At this stage (IIIa), generating multiple futures around each distinct policy goal will allow risk assessment
(IVe). To support risk assessment, Hulse et al. (2002) advocate using probabilistic approaches to generate multiple futures. Beck (2002) points out that all approaches that produce an ensemble of related futures (whether derived by probabilistic approaches or highorder belief-based models) are amenable to risk assessment. At the same time, Carpenter et al. (2003) suggest that the appropriate number of scenarios may be three or four, "more may confuse users and limit their ability to explore uncertainty.' Explicit replicable allocation rules allow variables to be selected to generate multiple futures.

Overall, the following criteria can be used to judge the adequacy of normative landscape scenarios that are intended to contribute to the science of landscape ecology at the same time as they contribute to landscape policy. The scenario components should:

- Be constructed in an iterative design process.

- Employ expert knowledge to hypothesize what landscape pattern characteristics will produce desired ecological and cultural effects.

- Integrate multiple disciplinary perspectives in the landscape futures for each scenario.

- Be imaginative, speculative, or didactic to inspire policy.

- Be plausible.

- Be replicable.

- Include adequate detail to meet both public and policy needs for realism and scientific needs for precision.

- Be constructed to allow investigation of pattern: process relationships and comparative evaluation of the alternatives.

\section{An example: Federal agricultural policy applied to Iowa watersheds}

We used a normative landscape scenario approach to examine Corn Belt agricultural landscape futures under different possible federal agricultural policies. Elsewhere, we have described the futures and their expected outcomes (Nassauer et al. 2002), and how we and our colleagues have evaluated the futures using disciplinary measures and models (e.g., Coiner et al. 2001; Vache et al. 2002; Rustigan et al. 2003), and pattern metrics (Corry 2002). In a related paper, our interdisciplinary group describes our integrated assessment comparing the futures (Santelmann et al. 2004). Below, referring to the questions in Table 1, 
we describe our method for developing these scenarios.

\section{Existing data. The past and present landscape: What is relevant about the existing landscape and its past?}

We selected our study area to be relevant to the overriding purpose of our research - to examine alternative scenarios that could enhance the indigenous biodiversity of agricultural landscapes. We also were opportunistic in choosing to use a very high resolution (3 meter) and richly detailed (37 classes) classification (based on Anderson Level II) GIS coverage of existing (1994) landcover that was developed as part of the Midwest Agrichemical Surface/subsurface Transport and Effects Research (MASTER) project (Freemark 1995; Waide and Hatfield 1995). Of six Iowa second-order watersheds for which such data had been encoded as part of MASTER, we chose two that represented different Corn Belt geomorphological and soil conditions to demonstrate futures for agricultural landscapes: Buck Creek in Poweshiek County (8,790 ha; 21,700 acres) and Walnut Creek in Story and Boone Counties (5,600 ha; 13,800 acres). These are described in detail elsewhere (Nassauer and Corry 1999; Santelmann et al. 2001; Nassauer et al. 2002).

After we had assembled a large interdisciplinary group to propose how the landscape should change (II $\mathrm{a}$ and $\mathrm{b}$ ), we acquired GIS coverages of detailed soils data including all soil phases at 0.8 hectare resolution ( Iowa State University 1996), USGS stream pattern data, and pre-settlement vegetation data drawn from the GLO survey of 1853-59 to enable us to allocate future landcovers. In addition, desirable landcover characteristics that were identified by our interdisciplinary group (IIb) led us to seek information about the finer scale spatial limitations of farming equipment and the dimensions of certain farming practices (e.g., strip intercropping). We used this information to construct rules for designing landscape patterns within polygons identified by the GIS-based land allocation model.

\section{Formulate hypotheses. Alternative future landscapes: How should the landscape change?}

We designed the scenarios using an iterative method (Figure 1) to address Question II (Table 1). We began by inviting a wide conversation among experts in ag- riculture and landscape ecology in an international LISTServ e-mail exchange about desirable future directions for US agricultural policy. From the LISTServ exchange we compiled a draft list of future landscape policy goals (IIa). These were reexamined and challenged in an intensive 3-day workshop where we engaged experts in agronomy, economics, forest ecology, geography, hydrology, landscape architecture and planning, policy, soil and water conservation, plant ecology, wetlands ecology, and vertebrate ecology in a series of field exercises in the study watersheds, critiques, and discussions for the purposes of: 1) determining what distinct policy goals were of interest both for policy-makers and as the basis for scientific questions, and 2) proposing what landscape characteristics would be likely to support those goals.

\section{IIa. Assumptions: Future landscape policy goals.}

Drawing upon the recommendations of workshop experts, we identified three distinct, contrasting plausible goals for agricultural landscape policy in the year 2025. Each of the three alternative scenarios assumed one of these policy goals. Scenario 1 emphasized the value of agricultural production (Figure 2), Scenario 2 emphasized the value of water quality (Figure 3), and Scenario 3 emphasized the value of biodiversity in the agricultural landscape (Figure 4). All three scenarios shared the assumption that the landscape would embody profitable agricultural production by private landowners in the year 2025 .

What made our assumptions about federal policy goals plausible was the wide range of conservation and habitat goals that have been addressed by federal agricultural policy - particularly since 1985 , when the Conservation Reserve Program was begun. What lent plausibility to our assumption that all scenarios would be profitable for farmers was the high proportion of US net farm income that is derived from federal government payments: $48 \%$ in 1999 (USDA 2001).

We chose these three sets of assumptions because we believed that the completed alternative futures would serve a didactic purpose, teaching policy-makers and the public about real choices for future agricultural policy, and because we thought that the contrasting scenario goals would allow disciplinary experts to formulate and test useful hypotheses about pattern:process relationships in a highly managed agricultural landscape. 


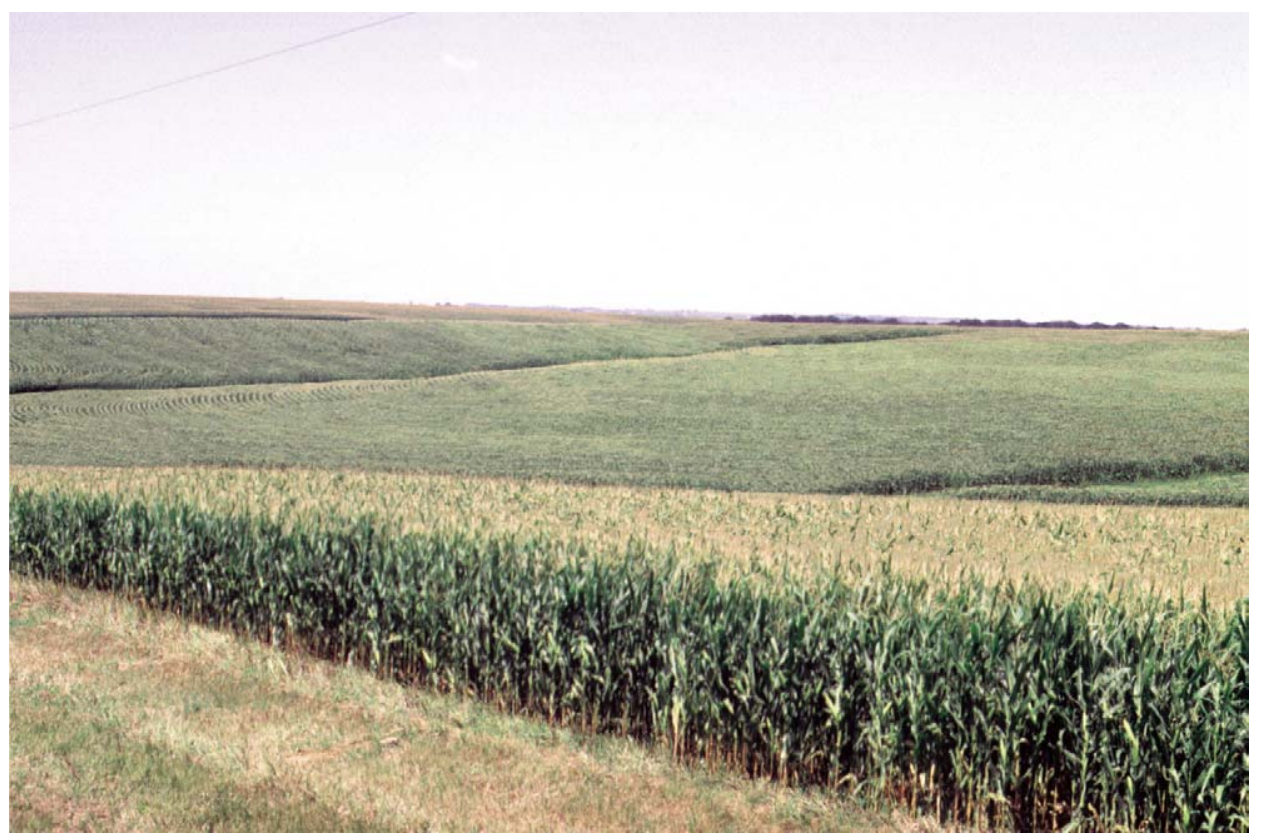

Figure 2. Scenario I emphasizes grain production, as illustrated by monoculture corn/soybean landcover in the rolling landscape of Buck Creek with a roadside in the foreground (Digital imaging simulation: R. Corry).

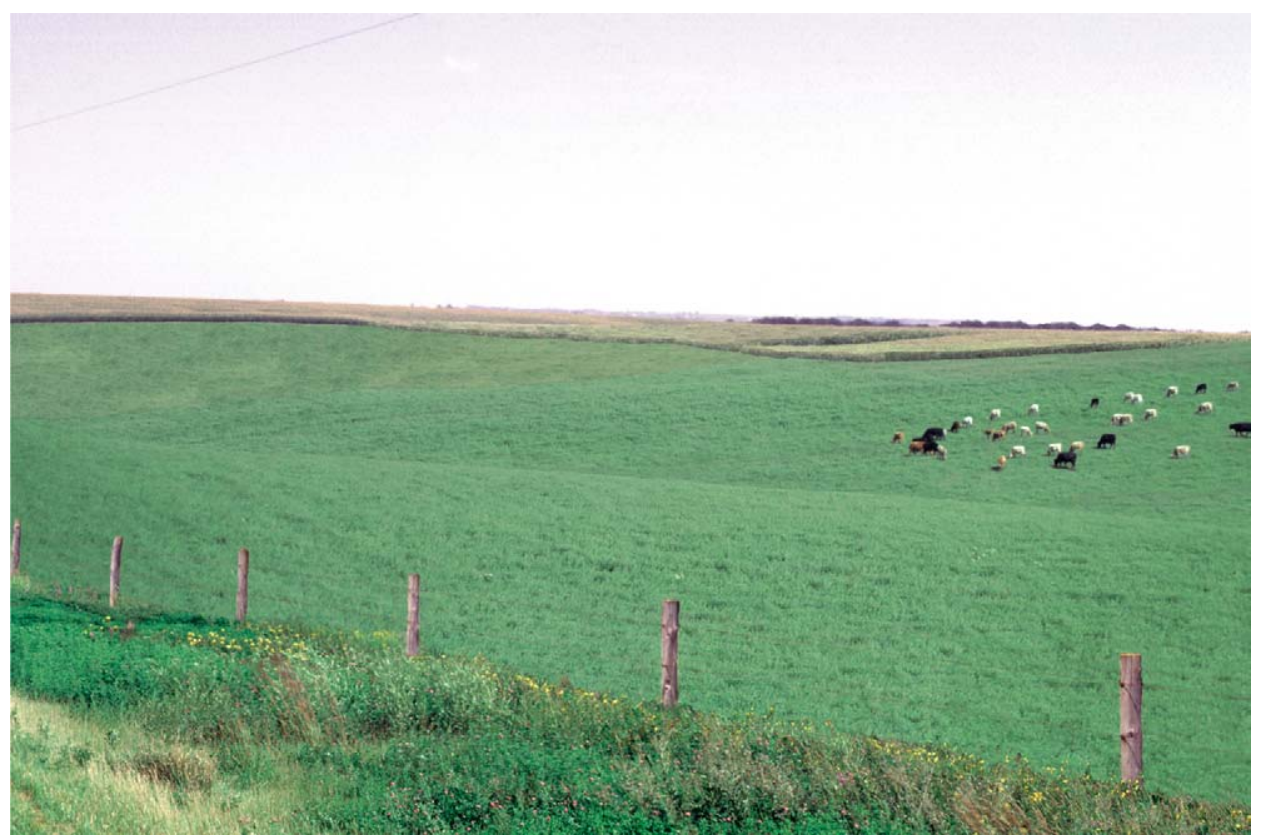

Figure 3. Scenario II landcover emphasizes water quality, as illustrated by extensive perennial grazing cover in Buck Creek (Digital imaging simulation: R. Corry). 


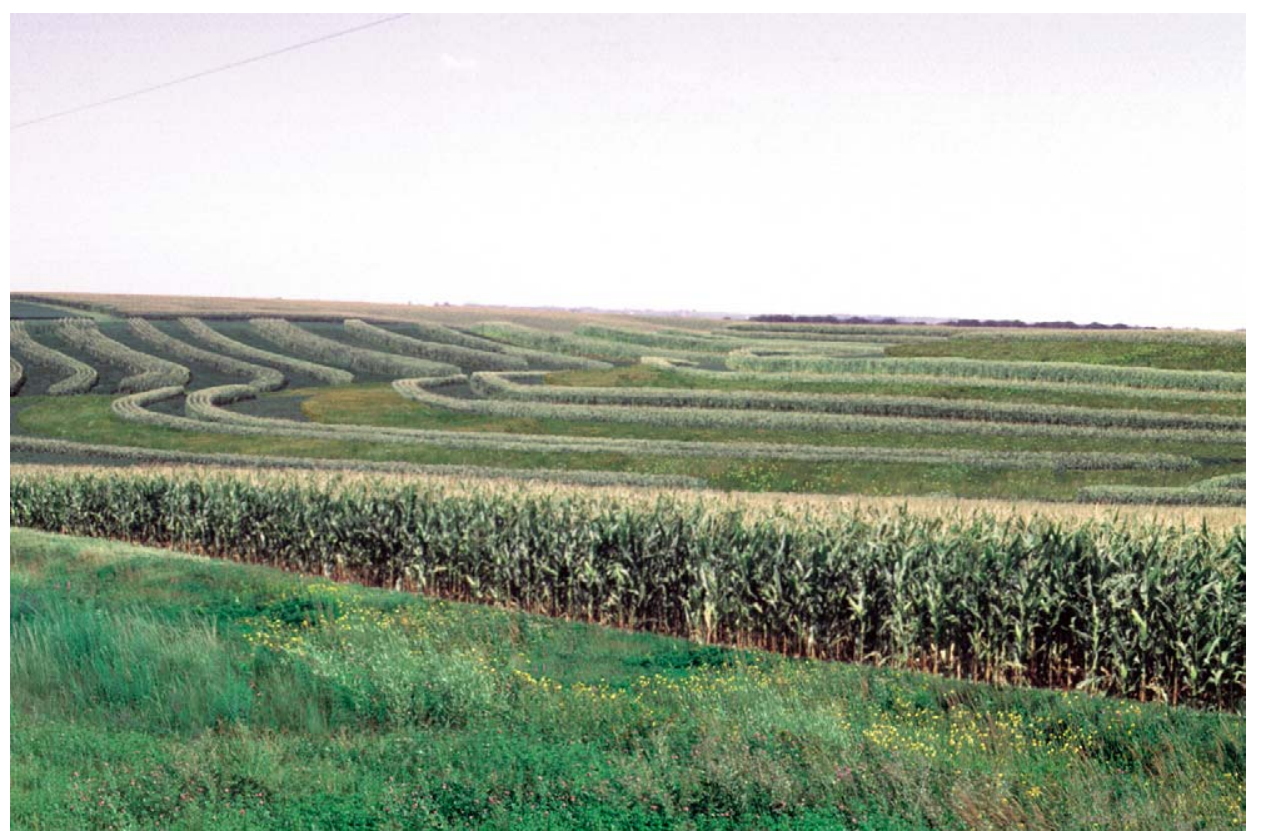

Figure 4. Scenario III landcover emphasizes biodiversity, as illustrated by an innovative strip intercropping pattern of corn, soybeans, and native prairie herbaceous cover in Buck Creek (Digital imaging simulation: R. Corry).

\section{IIb. Hypotheses: Desirable landscape characteristics.}

With these assumptions in mind, the experts proposed different desirable landscape characteristics for each of the three scenarios. These proposals were hypotheses to be tested by measurements, models, or metrics in the evaluation phase of the project (IV). The hypotheses were developed during the workshop in an interdisciplinary field exercise. While touring designated routes in the study watersheds in teams of 3-4 people, the experts developed spatially-explicit hypotheses for landscape patterns that could support each set of policy goals. These were presented, critiqued, and then revised in a workshop meeting of the whole to develop a menu of integrated, spatially-explicit proposals for landscape characteristics to meet policy goals.

\section{IIc. Operationalized hypotheses: Land allocation models.}

We translated and integrated these spatially-explicit proposals into land allocation models to generate alternative future landscape patterns (IIc and IIIa). If none of the workshop proposals addressed a question necessary to design an integrated landscape pattern to meet broader policy goals (IIa), we sought additional expertise: in aquatic ecology, in beef and dairy management, in perennial crop agriculture, and in organic agriculture. Trends within the two sample study watersheds that were not consistent with the larger Corn Belt landscape that they represented for this investigation were not included in the land allocation models. For example, population of rural areas in Iowa has declined over the past 60 years, while population of urban areas has grown or held steady (Goudy and Burke 1994). Walnut Creek watershed lies within the Ames-Des Moines growth corridor and is likely to continue to grow in population in the future. For the purposes of the models, it was treated as a more typical rural Corn Belt watershed, which will suffer population losses if farm sizes continue to grow.

We operationalized the desirable landcover characteristics for each of the scenarios as a set of precise decision-making rules (Nassauer and Corry 1999). Explicit decision-making rules for creating the futures also allowed our colleagues to consistently interpret the landcover classes of the futures when they measured or modeled the futures from their own disciplinary perspectives (IV).

We developed rule-based land allocation models at two scales. First, at a coarser grain applied across entire watersheds, we formulated nominal rules of com- 
bination as GIS algorithms (using 1994 landcover, pre-settlement vegetation, soils, and stream location coverages) to locate 2025 landcovers. Second-order rules were instructions for replicable design decisionmaking at finer scales not possible to locate with our 3-meter GIS coverages. For certain landcovers, we developed fine-grained rules based on dimensions of agricultural practices (e.g., best management practices for soil and water conservation, strip intercropping, precision agriculture patches) and spatial limitations of agricultural equipment (e.g., turning radii, maximum load /distance carried by a combine). For example, Scenario III assumes adoption of strip intercropping of corn and soybeans (Cruse 1990; Exner et al. 1999). GIS algorithms located perennial strip intercropping in quarter-quarter sections (16 hectares; 40 acres) that were adjacent to stream corridors or core biodiversity reserves in the Scenario III design. Then, within each designated field of perennial strip intercropping, we used rules describing fine-scale technological variables, like turning radii and load limitations of combines, to determine strip length and orientation across fields.

The draft landscape futures produced by our rules were reviewed by the disciplinary experts who were participants in our research project, as well as by others (Figure 1). Questions from these experts led us to further specify aspects of composition (e.g., species and age mix) and management that were relevant to models they planned to use to test the futures.

The new landcover data (III) were derived from both GIS allocation and more fine grained handdrawn design to be both were explicit (prescribed by rule) and precise (describing all characteristics of location, composition, configuration, or management that were needed to test the hypotheses in phase IV.) We allocated by rules in order to make the landscape futures replicable, allowing future tests of the hypotheses, and also to make the ways in which we 'implemented' our assumed policies clear for policymakers.

\section{New data. Alternative landscape futures: What is relevant about how the landscape could be?}

Each of the three futures is new data for testing a set of related hypotheses about public acceptance, economic return, and ecological and hydrological function based on landscape pattern. None is a prediction of the future. The alternative scenarios, the futures, and the expected performance of each future are de- scribed in Nassauer et al. (2002) and in Nassauer and Corry (1999). They are summarized in this issue in Santelmann et al. (2004).

The futures were designed at the same 3 meter (9.9 feet) resolution as the 1994 GIS landcover coverages. Innovative landcover patterns swelled the number of landcover classes to 86 in the 2025 futures coverages compared with 37 in the 1994 coverages. To illustrate how the futures were expected to affect ecological processes, Figure 5 interprets the landcover classes of each future compared with the present for it's expected effect on water quality.

To provide realistic images of futures for policy and to allow us to measure perception of the alternatives, we constructed digital imaging simulations of the futures. Within our study areas, we selected locations where landcover changed across the futures to illustrate their distinct characteristics. For these locations, we selected a single viewpoint, and simulated landcover for each future (Figure 2, Figure 3, Figure 4). Most of our simulations showed the landscape from a viewpoint on the ground. However, to allow respondents to view the broader landcover pattern for each alternative, we also simulated low-level aerial views of each watershed. We used these digital simulations in an informal survey of agricultural policy decision-makers (Nassauer and Corry 1999), and to measure Iowa farmers' perceptions of the futures.

We designed and encoded the futures in a way that allows experimentation with additional potential futures. We encoded the landscape matrix and network components (stream buffers and habitat reserves) of each scenario as discrete GIS coverages: conceptually interdependent to reflect the scenarios but spatially independent (Table 2). For example, the full implications of Scenario III are most validly embodied by combining Scenario III matrix design with Scenario III network design, but the Scenario III matrix design is complete as a landcover pattern without a network, and it could be combined with another network, for example Scenario II corridor design. This enabled the futures to be modeled in numerous ways, as whole concepts or as 'mix-and-match' landscape matrix and network components. Table 2 shows how the futures data structure provides coverages for constructing other futures for risk assessment (IV). 

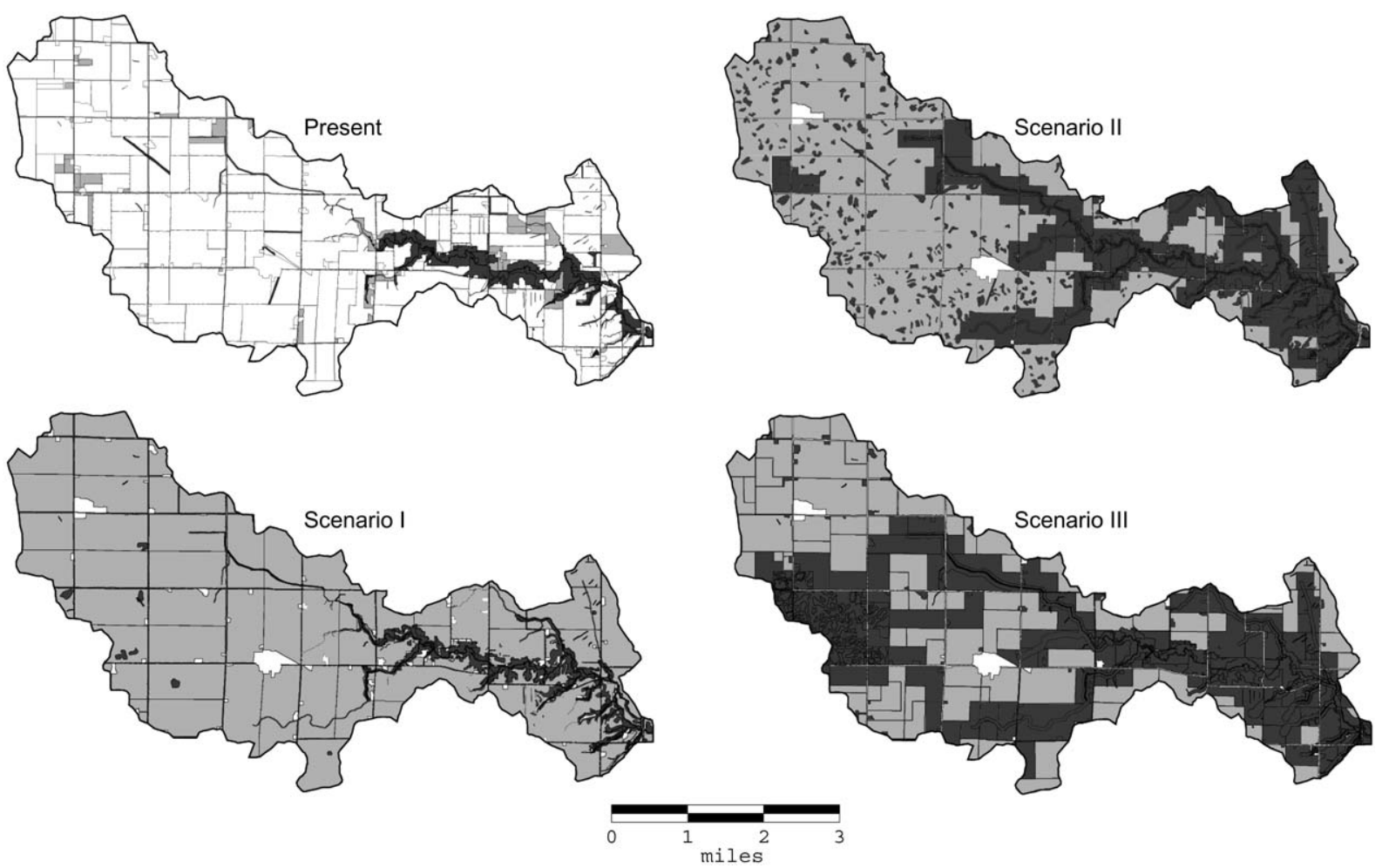

Figure 5. Landcovers that were expected to contribute to water quality benefits in each of the futures compared with the present for the Walnut Creek watershed (water quality benefits increase with dark tones).

Table 2. Landscape patterns that describe the primary futures and allow additional pattern combinations (x).

\begin{tabular}{|c|c|c|c|c|}
\hline \multicolumn{2}{|c|}{ Landscape Network Type } & \multicolumn{3}{|l|}{ Agricultural Matrix Type } \\
\hline $\begin{array}{l}\text { Buffer } \\
\text { width }\end{array}$ & $\begin{array}{l}\text { Reserve pres- } \\
\text { ence }\end{array}$ & $\begin{array}{l}\text { Scenario } 1 \text { (Production goal) } \\
\text { Coarse grain }\end{array}$ & $\begin{array}{l}\text { Scenario } 2 \text { (Water Quality goal) } \\
\text { Varied grain }\end{array}$ & $\begin{array}{l}\text { Scenario } 3 \text { (Biodiversity goal) } \\
\text { Fine grain }\end{array}$ \\
\hline $3-6 m$ & Reserves & $\mathrm{x}$ & $\mathrm{x}$ & $\mathrm{x}$ \\
\hline $3-6 m$ & No reserves & Future 1 & $\mathrm{x}$ & $\mathrm{x}$ \\
\hline $15-30-60 \mathrm{~m}$ & Reserves & $\mathrm{x}$ & $\mathrm{x}$ & $\mathrm{x}$ \\
\hline $15-30-60 \mathrm{~m}$ & No reserves & $\mathrm{x}$ & Future 2 & $\mathrm{x}$ \\
\hline $30-60-90 \mathrm{~m}$ & Reserves & $\mathrm{x}$ & $\mathrm{x}$ & Future 3 \\
\hline $30-60-90 \mathrm{~m}$ & No Reserves & $\mathrm{X}$ & $\mathrm{x}$ & $\mathrm{x}$ \\
\hline
\end{tabular}

\section{Test hypotheses. Evaluation of alternative} landscape patterns: How does their performance compare?

The range of models and empirical measures used to test hypothesized pattern:process relationships is described in Santelmann et al. (2004), which characterizes these evaluation methods by criteria that are relevant for decision-makers considering the policy and practices offered by these normative alternatives and also are relevant for scientists who wish to im- prove the accuracy of the evaluative metric or modeling approach for future applications: generality, realism, accuracy, precision, typical data availability, and scale of application. The futures were accessible both to methods that are high in realism (if low in generality) and methods that were high in generality (if low in realism) - spanning a range of disciplinary foci and information for policy-makers.

To date, the disciplinary evaluations and integrated assessment evaluate the three alternative futures in comparison with the present (e.g., Coiner et al. 2001; 
Corry 2002; Vache et al. 2002; Rustigan et al. 2003; Santelmann et al. 2004). In addition, the new data (Table 2) will allow future analysis of multiple futures that combine dimensions of the overriding scenario goals for risk assessment (IV. e).

\section{Conclusions}

All prospective scenarios can be powerful 'stimulants to our imagination' and 'a means to explore some of the critical choices that will, or could, influence the future' (p. 9; Hammond 1998). Given the capacity for humans (and policy) to change, normative scenarios might be characterized as reflecting an essential optimism about the ability of humans to make better decisions in the context of new information. We see landscape ecology concepts and questions as being ideally suited to provide substantive content for normative landscape scenarios, and normative scenarios as being one important scenario method for furthering the science of landscape ecology.

Normative landscape scenarios challenge both policy-makers and scientists to think about the future in a new way, as a tangible goal to explore rather than as a prediction about what might happen under certain circumstances. Scenarios that imaginatively depict plausible futures will meet resistance if they are treated as predictions. Because imagining even the most plausible futures is unfamiliar to most people, both cultural and institutional inertia lie between scenario design and policy development. The question of how to achieve new goals can be only partially suggested by scenarios. Based on his experience in the Netherlands, Schoonenboom observes that 'Future research should create countervailing ideas. The addressees of this type of information are seldom grateful for it. Nothing is easier than to stick to a generally accepted paradigm, by which priorities are nicely ordered...' (p. 20, 1995). Normative scenarios can be cognizant of institutional and cultural inertia without acquiescing to it. They can incorporate knowledge and methods of science without being constrained by misplaced paradigms of 'proof'. To do so, they must provide compelling and precise pictures of the future that can inspire speculative thought and be enriched by scientific knowledge. Knowing what landscape pattern to aim for may inspire new assumptions about what constitutes a plausible scenario and provoke policy-makers to be more inventive than they might otherwise have been. We see this mandate for imagi- native speculation in normative scenarios as a powerful means for science to influence policy - if normative scenarios are constructed with a clarity, discipline, and broad interdisciplinary consultation that enables science. The ideas and experience that we have related here are intended to invite further exploration of this potential.

\section{Acknowledgement}

We are deeply grateful to participants in the July 1997 Visioning Workshop in Ames, Iowa: Mimi Askew, Julia Badenhope, Joe Bernert, Lou Best, Mark Clark, Craig Cox, Rick Cruse, Brent Danielson, Joe Eilers, Kathryn Freemark, Susan Galatowitsch, Emily Green, Diane Hellekson, Tom Isenhart, Stan Johnson, Jo Ann Musumeci, Steve Polasky, Mary Santelmann, Carol Thompson, Ron Tuttle, and Denis White. For sharing their valuable knowledge and critique, we also thank Paul Anderson, Matthew Baker, Steve Barnhart, Wes Jackson, Calvin Johannes, Willie Lockeretz, Gerald Miller, Paul Opdam, Claire Vos, and Mike Wiley. Finally, for their thoughtful assistence in implementing the futures, we thank Elizabeth Foster, Christa Hawryluk, Rebecca Henry, Virginia Murphy, and Marilee Sundt.

\section{References}

Ahern J. 2001. Spatial concepts, planning strategies and future scenarios: A framework method for integrating landscape ecology and landscape planning.. In: Klopatek J. and Gardner R. (eds), Landscape Ecological Analysis: Issues and Applications. Springer-Verlag, New York, New York, USA.

Ahern J., France R., Hough M., Burley J., Turner W., Schmidt S., Hulse D., Badenhope J. and Jones G. 2002. Integrating ecology 'across' the curriculum of landscape architecture. In: Johnson B.R. and Hill K. (eds), Ecology and Design, Frameworks for Learning. Island Press, Washington, DC, USA, pp. 397-414.

Bantayan N.C. and Bishop I.D. 1998. Linking objective and subjective modeling for landuse decision-making. Landscape and Urban Planning 43: 35-48.

Beck M.B. 2002. Environmental Foresight and Models: A Manifesto. Elsevier Science, Kidlington, Oxford, UK.

Beck M.B., Chen J., Osidele O. 2002. Random search and the reachability of target futures.. In: Beck M.B. (ed.), Environmental Foresight and Models: A Manifesto. Elsevier Science, Kidlington, Oxford, UK, pp. 207-226.

Bierzychudek P. 1999. Looking backwards: assessing the projections of a transition matrix model. Ecological Applications 9: 1278 . 
Caza C. and Kaarik A.. 1994. Envisioning Future Canadian Landscapes: A Source Book. Wildlife Habitat Canada and the North American Waterfowl Management Plan, Ottawa, Canada.

Cocks D. 1999. Scenarios for Australian landscapes. Visions of Future Landscapes. Fenner Conference on the Environment, Canberra, ACT, Bureau of Rural Sciences, Kingston, Ontario, Canada, pp. 75-82.

Coiner C., Wu J. and Polasky S. 2001. Economic and environmental implications of alternative landscape designs in the Walnut Creek Watershed of Iowa. Ecological Economics 38: 119-139.

Cole S. 2001. Dare to dream: Bringing futures into planning. Journal of the American Planning Association 67: 372-383.

Corry R.C. 2002. A landscape index approach to evaluating the small mammal habitat quality of designed scenarios for agricultural watersheds. PhD Dissertation. University of Michigan, Rackham Graduate School, Ann Arbor, Michigan, USA.

Countryman D.W. and Murrow J.C. 2000. Economic analysis of contour tree buffer strips using present net value. Journal of Soil and Water Conservation 55: 152-160.

Cruse R.M. 1990. Strip intercropping.. In: Keeney D. (ed.), Farming Systems for Iowa: Seeking Alternatives. Leopold Center for Sustainable Agriculture, Ames, Iowa, USA, pp. 39-41.

Emmelin L. 1994. Landscape impact analysis: a human ecological approach to landscape futures.. In: Caza C. and Kaarik A. (eds), Envisioning Future Canadian Landscapes: A Source Book. Wildlife Habitat Canada and the North American Waterfowl Management Plan, Ottawa, Ontario, Canada, pp. 19-28.

Exner D.N., Davidson D.G., Ghaffarzadeh M., Cruse R. 1999. Yields and returns from strip intercropping on six Iowa farms. American Journal of Alternative Agriculture 14(2): 69-77.

Franklin J. and Forman R.T.T. 1987. Creating landscape patterns by forest cutting: ecological consequences and principles. Landscape Ecology 1: 5-18.

Freemark K. 1995. Assessing effects of agriculture on terrestrial wildlife: developing a hierarchical approach for the US EPA. Landscape and Urban Planning 31: 99-115.

Freemark K.E., Hummon C., White D., Hulse D. 1996. Modeling Risks to Biodiversity in Past, Present, and Future Landscapes. Canadian Wildlife Service Headquarters, Ottawa, Ontario, Canada, $60 \mathrm{p}$.

Fry G.L.A. 2001. Multifunctional landscapes - towards transdisciplinary research. Landscape and Urban Planning 57: 159-168.

Goudy W. and Burke S.C. 1994. Iowa's Counties: Selected Population Trends, Vital Statistics, and Socioeconomic Data. Census Services, Iowa State University, Ames, Iowa, USA, 427 p.

Gustafson E.J. and Crow T.R. 1998. Simulating spatial and temporal context of forest management using hypothetical landscapes. Environmental Management 22(5): 777-787.

Hamblin A. 1999. Visions of Future Landscapes. Fenner Conference on the Environment, Canberra, ACT, Bureau of Rural Sciences, Kingston, Ontario, Canada.

Hammond A.L. 1998. Which World? Scenarios for the 21st Century. Island Press, Washington, DC, USA.

Hansson L., Fahrig L., Merriam G. 1995. Mosaic Landscapes and Ecological Processes. Chapman \&Hall, London, UK.

Hobbs R. 1997. Future landscapes and the future of landscape ecology. Landscape and Urban Planning 37: 1-9.

Hulse D., Eilers J., Freemark K., Hummon C., White D. 2000. Planning alternative future landscapes in Oregon: Evaluating effects on water quality and biodiversity. Landscape Journal 19: $1-20$.
Hulse D., Gregory S. and Baker J., (eds) 2002. Willamette River Basin Planning Atlas. Oregon State University Press, Corvallis, Oregon, USA.

Iowa State University 1996. Iowa Soil Properties and Interpretations Database. Iowa State University, Ames, Iowa, USA, 28 p.

Jenerette G.D. and Wu J. 2001. Analysis and simulation of landuse change in the central Arizona-Phoenix region, USA. Landscape Ecology 16: 611-626.

Johnson G.D., Myers W.L. and Patil G.P. 1999. Stochastic generating models for simulating hierarchically sgtructured multicover models. Landscape Ecology 14: 413-421.

Jones S. 1999. Participation and community at the landscape scale. Landscape Journal 18: 65-78.

Keane R.E., Morgan P. and White J.D. 1999. Temporal patterns of ecosystem processes on simulated landscapes in Glacier National Park, Montana, USA. Landscape Ecology 14: 311-329.

Keitt T.H. 2000. Spectral representation of neutral landscapes. Landscape Ecology 15: 479-493.

Nassauer J.I. and Corry R.C. 1999. Rural Watersheds and Policy, World-Wide Web. Universal Resource Locator http://www.snre.umich.edu/nassauer/

Nassauer J.I., Corry R.C. and Cruse R.M. 2002. Alternative landscape future scenarios: a means to consider agricultural policy. Journal of Soil and Water Conservation 57: 44A-53A.

Opdam P., Foppen R. and Vos C. 2002. Bridging the gap between ecology and spatial planning in landscape ecology. Landscape Ecology 16: 767-779.

Pearson S.M., Turner M.G. and Drake J.B. 1999. Landscape change and habitat availability in the sourthern Appalachian highlands and Olympic Peninsula. Ecological Applications 9: 1288-1329.

Peterson G.D., Cumming G.S., Carpenter S.R. 2003. Scenario planning: a tool for conservation in an uncertain world. Conservation Biology 17: 358-366.

Ralls K. and Starfield A.M. 1995. Choosing a management strategy: Two structured decision-making methods for evaluating the predictions of stochastic simulation models. Conservation Biology 9: $175-181$.

Ribe R., Morganti R., Hulse D. and Shull R. 1998. A management driven investigation of landscape patterns of northern spotted owl nesting territories in the high Cascades of Oregon. Landscape Ecology 13: 1-13.

Risser P.G., Karr J.R. and Forman R.T.T. 1984. Landscape Ecology: Directions and Approaches. Illinois Natural History Survey, $22 \mathrm{p}$.

Rustigian H.L., Santelmann M.V. and Schumaker N.H. 2003. Assessing the potential impacts of alternative landscape designs on amphibian population dynamics. Landscape Ecology 18: 65-81.

RIZA 1996. Ecological networks in river rehabilitation scenarios: Rhine-Econet. M-Directorate - General for Public Works and Water Management: Ministry of Transport and Ministry of Agriculture, Lelystad, The Netherlands, $23 \mathrm{p}$.

Sala O.E., Chapin F.S.I., Armesto J.J., Berlow E., Bloomfield J., Dirzo R., Huber-Sanwald E., Huenneke L.F., Jackson R.B., Kinzig A., Leemans R., Lodge D.M., Moodey H.A., Oesterheld M., Poff N.L., Sykes M.T., Walker B.H., Walker M. and Wall D.H. 2000. Global biodiversity scenarios for the year 2100 . Science 287.

Samson F.B. and Knopf F.L. 1996. Putting 'ecosystem' into natural resource management. Journal of Soil and Water Conservation 51: 288-292. 
Santelmann M., Freemark K., White D., Nassauer J., Clark M., Danielson B., Eilers J., Cruse R., Galatowitsch S., Polasky S., Vaché K. and Wu J. 2001. Applying ecological principles to land-use decision-making in agricultural watersheds.. In: Dale V.H. and Haeuber R.A. (eds), Applying Ecological Principles to Land Management. Springer-Verlag, New York, New York, USA, pp. 226-252.

Santelmann M., White D., Freemark K., Nassauer J., Eilers J., Vaché K., Danielson B., Corry R., Clark M., Polasky S., Cruse R., Sifneos J., Coiner C., Wu J. and Debinski D. 2004. Assessing alternative futures for agriculture in the U.S. Cornbelt. Landscape Ecology 19: 357-374.

Schoonenboom I.J. 1995. Overview and state of the art of scenario studies for the rural environment.. In: Schoute J.F.T., Finke P.A., Veeneklass F.R. and Wolfert H.P. (eds), Scenario studies for the rural environment. Kluwer, Dordrecht, The Netherlands, pp. 1524.

Science Advisory Board 1995. Beyond the Horizon: Using Foresight to Protect the Environmental Future. US Environmental Protection Agency, Washington, DC, USA.

Schwartz P. 1991. The Art of the Long View. Doubleday, New York, New York, USA.

Steinitz C. 1990. A framework for theory applicable to the education of landscape architects (and other environmental design professionals). Landscape Journal 9: 136-143.

Steinitz C. and MacDowell S. 2001. Alternative Futures for Monroe County Pennsylvania.. In: Dale V. and Haeuber R.A. (eds), Applying Ecological Principles to Land Management. SpringerVerlag, New York, New York, USA.

Steinitz C., Arias H., Bassett S., Flaxman M., Goode T., Maddock III T., Mouat D., Peiser R. and Shearer A. 2003. Alternative Futures for Changing Landscapes: The Upper San Pedro River Basin in Arizona and Sonora. Island Press, Washington, DC, USA.

Steinitz C. 2002. On teaching ecological principles to designers.. In: Johnson B.R. and Hill K. (eds), Ecology and Design. Island Press, Washington, DC, USA, pp. 231-244.

Swetnam R.C., Ragou P., Firbank L.G., Hinsley S.A. and Ballamy P.E. 1998. Applying ecological models to altered landscapes: scenario-testing with GIS. Landscape and Urban Planning 41: $3-18$.
Tilman D., Fargione J., Wolff B., D'antonio C., Dobson A., Howarth R., Schinder D., Schlessinger W.H., Simberloff D., Swackhamer D. 2001. Forecasting agriculturally driven global environmental change. Science 292: 281-284.

Tischendorf L. 2001. Can landscape indices predict ecological processes consistently? Landscape Ecology 16: 235-254.

Tress B. and Tress G. 2003. Scenario visulization for participatory landscape planning - a study from Denmark. Landscape and Urban Planning. In Press.

Turner M.B. and Romme W.H.. 1994. Landscape dynamics in crown fire ecosystems. Landscape Ecology 9: 59-77.

Turner M.G., Gardner R.H. 2001. Landscape Ecology in Theory and Practice: Pattern and Process. Springer - Verlag, New York, New York, USA.

USDA 2001. Food and Agricultural Policy. Taking Stock for a New Century. Washington, DC, USA.

Vaché K., Eilers J. and Santelmann M. 2002. Water quality modeling of alternative agricultural scenarios in the U. S. Corn Belt. Journal of the American Water Resources Association. 38: 773787.

Varis O. 2002. Belief networks: Generating the feared dislocations.. In: Beck M.B. (ed.), Environmental Foresight and Models: A Manifesto. Elsevier Science, Kidlington, Oxford, UK, pp. 169205.

Wachs M. 2001. Forecasting versus envisioning: A new window on the future. Journal of the American Planning Association 67: 367-373.

Waide J.B. and Hatfield J.L. 1995. Preliminary MASTER assessment of the impacts of alternative agricultural management practices on ecological and water resource attributes of Walnut Creek watershed, Iowa. FTN Associates Limited, Little Rock, Arkansas, USA.

White D., Minotti P.G., Barczak M.J., Sifneos J.C., Freemark K.E., Santelmann M.V., Steinitz C.F., Kiester A.R. and Preston E.M. 1997. Assessing risks to biodiversity from future landscape change. Conservation Biology 11: 349-360.

Wickham J.D., O'Neill R.V. and Jones K.B. 2000. A geography of ecosystem vulnerability. Landscape Ecology 15: 495-504. 